Protestantismo em Revista é licenciada sob uma Licença Creative Commons.

http://dx.doi.org/10.22351/nepp.v43i2.3042

\title{
Sistema de crenças: uma conceituação
}

\author{
System of belief: a concept
}

Gilson Xavier de Azevedo*

Carolina Teles Lemos**

\begin{abstract}
Resumo
Este artigo tem por objetivo estabelecer um diálogo com os conceitos de sistema, crença e sistema de crenças permeado pelas noções de consciência e realidade. Justifica-se o presente estudo, dado o crescimento de pesquisas e produções sobre o referido tema. A metodologia adotada é a de um estudo revisional exploratório de caráter bibliográfico. A questão básica é considerar se é possível pensar um sistema de crenças na condição de uma estrutura, tal qual a cultura, a economia e a educação. A premissa básica é de que o chamado sistema de crenças seria na realidade uma estrutura que cria, permeia e reconfigura as demais estruturas existentes. Aponta-se como resultado a ampliação dessa discussão e a construção de formulações que permitem debates mais amplos sobre o tema.
\end{abstract}

\section{Palavras-chave}

Sistema. Crença. Sistema de Crenças.

\begin{abstract}
This article aims to establish a dialogue with the concepts of system, belief and belief system permeated by the notions of consciousness and reality. The present study is justified, given the growth of researches and productions on this theme. The methodology adopted is that of an exploratory review of a bibliographic character. The basic question is
\end{abstract}

[Texto recebido em junho de 2017 e aceito em janeiro de 2018, com base na avaliação cega por pares realizada por pareceristas ad hoc]

* Pós-Doutorado em andamento (Lusófona, Porto). Doutor em Ciências da Religião (PUC-GO) com bolsa da FAPEG. Mestre em Ciências da Religião (PUC-GO) com bolsa da FAPEG. Pós-Graduado em Administração Escolar e Coordenação Pedagógica (UVA-RJ), Ética e cidadania (UFG). Filósofo Clínico (Inst. Packter/PUC). Filósofo (Dom Felício/FAEME). Pedagogo (UVA-ACARAÚ). Teólogo (FAETEL/MACKENZIE). Professor Titular de Antropologia pela FAJOP, Filosofia do Direito e Filosofia Empresarial pela FAQUI. Coordenador do Núcleo de Apoio à Educação à distância pela FAQUI (NAED). Docente Efetivo da Universidade Estadual de Goiás, Câmpus Quirinópolis. Docente convidado de PósGraduação pela UEG, Câmpus Mineiros. Docente convidado e ex-preceptor do curso de Pedagogia pela UNIUBE. Ex-coordenador do curso de Pedagogia da UEG. Articulista. Ex-vereador suplente eleito por Quirinópolis (2012-2016). Avaliador de cursos do Guia do Estudante. Editor das Revista REEDUC-UEG, ANAIS SIMPED UEG, RECIFAQUI. Palestrante e conferencista com mais de 200 horas de atividades proferidas. E-mail: gilson.azevedo@ueg.br

** Professora Titular no Programa de Pós-Graduação em Ciências da Religião da PUC-GO. Doutorado em Ciências Sociais e da Religião (UMESP). Investiga temas como: religião e saúde, religião e gênero, religiões populares, dentre outros. E-mail: cetelemos@uol.com.br 
whether it is possible to think of a belief system as a structure, such as culture, economics and education. The basic premise is that the so-called belief system would actually be a structure that creates, permeates, and reconfigures the other existing structures. As a result, the expansion of this discussion and the construction of formulations that allow broader debates on the theme is a result.

\section{Keywords}

System. Belief. System of Belief.

\section{Introdução}

$\mathrm{O}$ ato de crer é próprio do humano. Somo seres da crença, da crendice que é a crença sem senso crítico, do crer e do acreditar. Professamos crenças e credos diariamente, mas cabe averiguar inicialmente o que é então uma crença e por que ela parece ser tão inerente ao ser humano?

Para Champlin, no verbete crença (crer), se diz que "a crença é mais forte que a opinião e mais fraca que o conhecimento". ${ }^{1}$ Somente esta proposição é suficiente para se perceber que a crença é de início um estado da mente e um estágio do pensamento. Crença, opinião e conhecimento são momentos distintos do pensamento, em que, aquele que crê em algo, o faz porque detém uma proposição ou premissa em função de uma verdade a qual pretende alcançar ou afirmar.

Bell, Halligan e Ellis estabelecem uma distinção importante nesse universo das crenças que são as crenças raízes se referindo àquelas que são ativamente pensadas e fala das crenças disposicionais ou sem reflexão. ${ }^{2}$

O conceito de crenças, por sua vez, remete a um conceito mais amplo que é o conceito de Sistema de Crenças. Até bem pouco tempo tinha-se a ideia de que a estrutura humana denominada cultura era a maior estrutura da qual decorriam todas as demais. Entretanto, atualmente discute-se no meio acadêmico uma estrutura humana mais significativa e sem a qual, nem a cultura subsiste, que é o sistema de crenças.

Um sistema de crenças reúne crenças e valores compartilhados por uma determinada cultura, que definem nesse conjunto, um modo específico de perceber o mundo social, cultural, físico e psicológico, o qual afeta diretamente nosso estado de consciência e nossa compreensão daquilo que formulamos como realidade. A maneira como compreendemos o real e os adjetivos que a ela atribuímos é construída em nosso sistema de crenças.

O conjunto de valores de uma cultura e nossa aceitação ou rejeição destes valores são frequentemente baseados em nosso próprio sistema de crenças cultural. A forma como

1 CHAMPLIN, R. Enciclopédia de Bíblia, teologia e filosofia. São Paulo: Candeia, 2005. p. 952. Verbete: crença.

2 BELL, V.; HALLIGAN, P. W.; ELLIS, H. D. A Cognitive Neuroscience of Belief. In: HALLIGAN, Peter W.; AYLWARD, Mansel. The Power of Belief: Psychological Influence on Illness, Disability, and Medicine. Oxford: Oxford University Press, 2006. 
lidamos com nossa saúde e com situações de doença, seja nossa ou de outrem, também encontra respaldo em nosso sistema de crenças. Este é construído tanto a partir da maneira como se vê e interage com o que para o indivíduo torna-se realidade, quanto pode ser impresso em nossa consciência.

Desse modo, pode-se falar de Sistemas de crença primários ou que estão presentes em nossa consciência desde o nosso nascimento, quanto podemos nos referir a níveis históricos, sociais, culturais, religiosos, psíquicos, emocionais, racionais, filosóficos, genéticos, biológicos, físicos, espirituais e muitos outros.

No afã de construir uma perspectiva conceitual do que seja sistema de crenças, adota-se por metodologia uma análise exploratória de autores e referências bibliográficas, considerando inicialmente o conceito de sistema na perspectiva sociológica de Rombach, ${ }^{3}$ em seguida busca-se conceituar a ideia de Crenças dentro da Filosofia clássica e Moderna, tendo por referência Abbagnanno ${ }^{4}$ e, por fim, adota-se da perspectiva de Luhmann $^{5} \mathrm{o}$ conceito de estrutura para então formular o conceito de Sistema de Crenças.

Usando uma metodologia padrão, espera-se alcançar algumas elucidações sobre o tema proposto, dado que nota-se um avanço nas discussões do referido, de modo que acredita-se ampliar substancialmente a preocupação nos campos Filosófico, Sociológico e Antropológico sobre o papel das crenças em nosso cotidiano, sociedade e cultura.

\section{O conceito de sistema}

A antropologia estrutural ${ }^{6}$ de Heinrich Rombach ${ }^{7}$ é a teoria segundo a qual a ideia de sociedade como sistema mostra-se diretamente como uma sociologia romântica que não caberia mais em nossos dias.

Parte-se do pressuposto de que três princípios ontológicos norteiam tal proposição, a saber: substância, sistema e estrutura. $O$ primeiro deles centra-se na percepção de que a sociedade tem por origem e manutenção nas relações sociais. Aqui a sociedade não existe por si só, de modo que a concepção de sistema seria secundária direcionada às máquinas e aos aparelhos elétricos.

A ideia de sistema não compreende as relações sociais a partir do indivíduo e sim a partir da sociedade, sendo este, apenas um aspecto periférico. O conceito de sociedade enquanto estrutura compreende uma autoconstrução e possibilidade de autoeliminação.

3 ROMBACH, Heinrich. Leben des Geistes: Ein Buch der Bilder zur Fundamentalgeschichte der Menschheit. Freiburg/Basel/Wien: Herder, 1977.

4 ABBAGNANO, Nicola. Dicionário de filosofia. São Paulo: Martins Fontes, 2000.

5 LUHMANN, Niklas. Funktion der Religion. Frankfurt am Main: Suhrkamp, 1977.

6 O autor tratou desse tema e especialmente da teoria do sistema de Nikklas Luhmann em "Estrutura e sistema".

7 O Prof. PhD Heinrich Rombach, nascido em 1923, lecionou Filosofia na Universidade de Würzburg. Nesta obra, ele desenvolve três princípios interdependentes: ontologia estrutural, hermetismo, filosofia da imagem. Cf. ROMBACH, 1977. 
Nesse contexto, o ser humano é uma estrutura não apenas como indivíduo, mas também como sociedade. Nenhum dos dois é o último, mas estão ambos sempre ligados, um ao outro em diferentes graus.

A vida social só conserva sua vivacidade quando essa multidimensionalidade do ser social é mantida. Se o indivíduo fosse defrontado, como um todo, substancial e imediatamente com o sistema social, isso não conduziria a nenhuma estrutura viva nem a uma vida social liberal. Um faria o outro fracassar. O individualismo extremo é tão absurdo e irrealizável quanto o socialismo extremo. Isso se mostra em toda a sua clareza onde o socialismo ontológico - não apenas aquele que existe de fato - fracassa em sua insuficiência. ${ }^{8}$

É possível notar que a concepção de indivíduo enquanto estrutura e não como parte do todo compreende os campos orgânico-corporal e psíquico-espiritual, de modo que suas forças e habilidades não se apresentam de forma simples, precisam ser "estruturadas" por ele, isto é, levadas a uma constelação que conduz cada momento à fecundidade máxima e ao apoio e colaboração contíguos.

Pode-se pensar, portanto, qualquer uma das dimensões humanas como no caso da liberdade que em Rombach existe tanto como estado interior de um indivíduo na condição de adequação de sua estrutura social, quanto em sua exterioridade, na condição de coerção. ${ }^{9}$ Desse modo, as estruturas formam uma só estrutura, uma imbricada, porém nunca perfeita, pronta, de modo que, "tudo o que o indivíduo principia por si mesmo tem sempre também um aspecto social; tudo o que se faz na sociedade tem sempre também um aspecto individual". 10

Para entender tal proposição, pode-se citar o fato de que uma estrutura racista poderá produzir estruturas ou pessoas racistas por fenômeno de correspondência. De mesmo modo, uma sociedade religiosa só se faz se, nesta, houver muitas pessoas religiosas. Aqui, situo na questão de sistema, a questão da crença, ou seja, como imaginários como o racismo se propagam? Como tal crença, e outras tantas se constroem?

Nesse contexto, pode-se entender que a medicina popular, seria uma estrutura que está presente na vida humana há milhares de anos e que tal estrutura não foi nem abandonada, nem suplantada pela medicina oficial, apenas que esta é uma variação daquela. Assim, pretende-se a seguir discorrer sobre tais vertentes buscando estreitar a compreensão do fenômeno da medicina popular, frente o proposto na teoria de Rombach. ${ }^{11}$

\footnotetext{
ROMBACH, 1977, s. p.

9 ROMBACH, 1977, s. p.

10 ROMBACH, 1977, s. p.

11 ROMBACH, 1977, s. p.
} 
Esse conjunto de informações permite entender que a sociedade pensada por Rombach acontece simultaneamente com o indivíduo, sem transcendê-lo, sem suprimilo. ${ }^{12}$ Assim, a antropologia estrutural é uma fenomenologia crítica, na medida em que busca entender fenômenos completos presentes nos epifenômenos sociais.

Os fenômenos humanos já estão por si mesmos, em um caminho e se apresentam sempre em graus diferenciados de desenvolvimento. Eles nunca simplesmente existem, mas têm sua própria profundidade existencial, na qual se atiram de modos diferentes e atingem diferentes profundidades em tempos também distintos. Assim, eles só se dedicam totalmente à clareza de sua forma real, quando se baseiam em sua própria profundidade existencial. ${ }^{13}$

Estando inserido em uma estrutura social e sendo ele mesmo esta estrutura, o homem social cria estruturas de poder, propriedade, linguagem idioma que acabam por determinar sua razão. O indivíduo não se vê mais voltado para o absoluto, o espiritual, mas está totalmente conectado à sociedade que lhe impõe sua estrutura como fundamento da vida, do pensamento e do ser. Sua força agora não é exterior, mas interna. É seu conjunto de crenças que lhe dá segurança existencial e lhe permite se situar no mundo.

Nesse contexto, a evolução do homem de uma condição primitiva a uma condição racional só foi possível a partir do momento em que ele construiu e aceitou as formas de sentir, pensar e agir logicamente. Para Rombach,

o homem até se tornou "social", mas a sociedade não se tornou "humana", dado que algumas crenças parecem funcionar bem de dentro para fora e não tão bem de fora para dentro. Assim, o programa do homem "social", bem como o programa do homem "individual" (isto é, livre) naufragaram. Neste ponto começa a surgir a ideia de "homem humano". ${ }^{14}$

O processo humano daquilo que Rombach chama de "concreação", acontece a partir de um processo de autogênese, de modo que começa sobremaneira a partir da Renascença a se ver como centro, como pessoa, como algo no mundo e é justamente nesse momento que passa à construção coletiva da sociogênese. ${ }^{15}$

Em campos como a medicina, o processo evolutivo levou milhares de anos para se consumar no que se convencionou chamar de medicina contemporânea. Fato é que as crenças humanas são o que de mais humano existe e estão imbricadas pelo desenvolvimento de outras áreas do saber como a antropologia, a química e a agricultura, bem como situam-se na origem de toda e qualquer formação cultural.

\footnotetext{
12 ROMBACH, 1977, s. p.

13 ROMBACH, 1977, s. p.

14 ROMBACH, 1977, s. p.

15 ROMBACH, 1977, s. p.
} 
Pensando agora esta relação entre homem e natureza a partir da lógica do trabalho, Rombach entende que:

Os fenômenos fundamentais da existência humana estão estreitamente imbricados. Eles não podem ser separados uns dos outros, mas talvez diferenciados entre si. Por exemplo, um artefato é ao mesmo tempo uma produção técnica e artística, como é o caso da Torre de Pisa. Porém ela se apresenta nas diferentes ordens respectivamente como um fenômeno diferente: como produção técnica ela fracassou (sobretudo por causa da curva no pavimento superior); como produção artística ela é um documento primoroso da Renascença italiana. ${ }^{16}$

Desse modo, o que marcou a passagem de um fato arquitetônico e de engenharia para uma convenção artística se não as crenças ao redor do fato? Nesse sentido, as práticas humanas servem a propósitos diferentes e em diferentes circunstâncias pode servir ou gerar novos propósitos como é o caso do Sistema de Crenças. De um propósito arquitetônico, pode assumir ao longo da história propósitos outros, relacionados não apenas ao imaginário coletivo.

A história da sociedade nos ensina muito sobre as transposições entre ordem de trabalho e ordem profissional. Por exemplo, um trabalho que antigamente era atividade secundária de mercador ambulante, praticada em feiras, como a extração de dentes, no decorrer dos séculos tornou-se uma respeitável profissão, acompanhada de um característico orgulho profissional.17

Desse modo, a estrutura social vai se articulando e constituindo aquilo que Rombach chama de "ordem", podendo originar além da já citada ordem das profissões, a ordem econômica, a ordem moral, a ordem linguística e a língua como ordem transcendental. ${ }^{18}$

Para Rombach,

Se nos aproximarmos mais, agora, do fenômeno da ocorrência linguística, então veremos que aqui também a lei fundamental das ordens sociais se repete, ou seja, que ela é o pressuposto transcendental para cada fato pertencente a essa ordem e que essa predeterminação transcendental mesma surge e se desenvolve de maneira viva. Palavras isoladas obtêm seu significado não só por meio da relação imediata com o objeto nelas declarado, mas, sim, por meio de sua 'tensão' relacional no todo da língua como organismo. ${ }^{19}$

\footnotetext{
ROMBACH, 1977, s. p.

ROMBACH, 1977, s. p.

18 ROMBACH, 1977, s. p.

19 ROMBACH, 1977, s. p.
} 
Desse modo, as ordens dentro dos processos de estruturação do humano e da sociedade, são um fenômeno multiforme e não poderiam ser de outro modo, pois o próprio ser humano o é. O eu deve ser em Rombach outro eu que ainda não foi alcançado, feito, construído e que se perfaz por meio de suas crenças individuais e coletivas.

Antes de tudo, é como se a língua não fosse uma ordem em si, mas um meio que é empregado em todas as ordens, na ordem de trabalho e na econômica, assim como na ordem da moradia, do direito, da propriedade, da religião, da arte, da filosofia etc. Nenhuma dessas ordens poderia ser realizada se a língua, como meio, não penetrasse nelas e cuidasse do intercâmbio que, afinal, as legitima. ${ }^{20}$

Nesse contexto, pode-se pensar que a crença, em vez de um simples epifenômeno, seria uma ordem, que poderia ser chamada aqui de mental, pois seu desenrolar secular, não fugiu em nenhum momento dessa denotação de dar nome às coisas e ao mundo, de localizá-las e situá-las.

Historicamente não faltaram momentos em que a ordem mental esteve ainda associada à religiosa no que concerne ao cotidiano, eternidade, tempo, divindade e humanidade. Assim, a religião enquanto ordem serve tanto para o homem contemporâneo dar sentido ao seu cotidiano, como à cultura, economia, ciência doença, saúde, cura, remédio, medicina, fé, crença e integração homem-natureza.

Niklas Luhmann (1927-1998) um dos mais importantes representantes da atual Sociologia alemã, constrói sob a ótica da questão da comunicação, a teoria conhecida por "Sistemas Sociais" em que a sociedade é um sistema definido pela fronteira entre o indivíduo e o ambiente e estando assim separado de um exterior infinitamente complexo. Nesse contexto, a comunicação no interior desse sistema atua seccionando uma quantidade limitada de informação disponível no exterior.

A teoria social de Niklás Luhmann é construída a partir de um contexto de Guerra Fria (1970-1980), sendo pensada sob uma ótica que analisa pontos relevantes do tecnicismo e cientificismo pós-moderno e de um possível aprisionamento simbólico do indivíduo nessa teia.

A sociedade identificada por Luhmann em A sociedade da sociedade compreende sua mais ampla concepção de sociedade, englobando os vários meandros desta teoria. ${ }^{21}$ Mathis expõe que alguns autores teriam influenciado Luhmann dadas as publicações que construíram; são eles: Foerter, Prigogine, Haken, Eigen e Holling. ${ }^{22}$ Os autores abordaram

20 ROMBACH, 1977, s. p.

21 LUHMANN, Niklas. Die Gesellschaft der Gesellschaft. Frankfurt am Main: Suhrkamp, 1997.

22 MATHIS, Armin. A sociedade na teoria dos sistemas de Niklas Luhmann. Presença, v. VIII, n. 28, maio 2004. Disponível

em: <http://www.revistapresenca.unir.br/artigos_presenca/28arminmathias_asociedadenateoriadossistema s.pdf>. Acesso em: 17 jun. 2012. p. 3. 
opiniões científicas sobre a ciberorganização, a termodinâmica não linear, o conceito de auto-organização a seleção molecular e a questão da resiliência social respectivamente.

Dentro da lógica sistema social-comunicação-pensamento, Luhmann entende que as comunicações, quaisquer que sejam, se produzem por meio dos pensamentos, sendo que esta comunicação só acontece socialmente, ou seja, onde o homem estiver, pois fora desse sistema, não há nem pensamento, muito menos sociedade. ${ }^{23}$

O que até então era concebido dentro do âmbito da sociedade como sistema aberto, onde a liberdade humana tendia ao dimensionamento da vontade natural, passa a partir da construção de autopoiesis a ser visto como um sistema social fechado em que o sistema social de Luhmann, conforme Mathis, ${ }^{24}$ é por si só autônomo por ser fechado e não atuar além desse espaço que é ao mesmo tempo simbólico (pensamento) e real (meio).

A crença nesse caso, é um sistema de concreação, um sistema fechado que ao mesmo tempo o que constrói a realidade, a permeia e a renova. A mescla desses dois

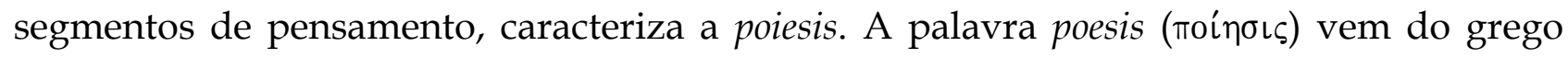
significando inicialmente criação, ação, confecção e fabricação. Tem por sentido o ato de sistematizar, observar qualificando e quantificando.

Nesse contexto, a construção social do indivíduo se dá por autopoiesis, ou seja, simultaneamente em seu pensamento e no meio em que está. Na autopoiesis o meio tornase base, mas não pressuposto, pois o sistema social nasce e finda na autopoiesis; esse simplesmente está em seu meio.

A crença é um elemento autopoiético justamente porque o indivíduo, mesmo em sonho, pensa a si mesmo, imagina-se e pensa seu próprio ser, corpo, estética, sociabilidade a partir de mecanismos internos e imaginários.

De acordo com a leitura de Mathis, os sistemas se formam a fim de reduzir a complexidade do mundo e sua constelação de elementos sendo infinitamente combinados entre si e acontecendo que contém todos os sistemas e todos os meios. ${ }^{25}$ A complexidade do mundo nesse sentido é sempre maior que a complexidade do meio e a própria condição de contingência do indivíduo nesse meio, ou seja, as coisas são assim, mas poderiam ser diferentes.

Todavia, para Willke, a Complexidade (mundo) e a Contingência (meio) são diferentes e podem ou não coincidir em uma situação. ${ }^{26} \mathrm{Na}$ mesma situação, um mesmo indivíduo pode agir dessa ou daquela maneira.

\footnotetext{
3 LUHMANN, 1997.

MATHIS, 2004.

25 MATHIS, 2004, p. 5.

26 WILLKE apud MATHIS, 2004, p. 6.
} 
Para Luhmann, o que regula a seleção de dados do meio para compor o sistema é um conjunto de preferências também chamadas por ele de sentido formando, assim, a condição de possíveis desse sistema. ${ }^{27}$ Nesse sentido, o sistema é sempre imprevisível (reentry), ou seja, carrega em si um potencial imenso de surpresas que precisam ou que o indivíduo terá a necessita de identificá-las e transformar isso em informação.

Em resumo, Mathis explica que não se pode sair da sociedade para descrevê-la dado que esta é um espectro que existe no indivíduo. ${ }^{28}$ Extrapolando o conceito, se poderia dizer que a sociedade é o próprio indivíduo, embora, seja o conceito de sociedade, formado por indivíduos concretos de comum consenso conceitual e somatório de todas as comunicações que nela ocorrem.

Esse conceito pós-estruturalista retoma a ideia de que "os limites da minha linguagem são os limites do meu mundo", 29 representando, com isso, a posição. Em outras palavras, os limites da sociedade são os limites da comunicação e tudo o que não for comunicação não estará contido no sistema.

De acordo com Kunzler, faz-se necessário superar três obstáculos em relação à separação de sistema e ambiente: "o primeiro deles é a premissa de que a sociedade é constituída de pessoas e de relações entre pessoas. $\mathrm{O}$ segundo obstáculo epistemológico diz que as sociedades têm fronteiras territoriais e/ou políticas. [...] O terceiro obstáculo é a separação entre o sujeito e o objeto". 30

\section{Conceito de crença}

Como já foi enunciado nesse artigo, a palavra crenças assume diversas denotações e conotações. Cabe ao texto esclarecer tal conceito e relacioná-lo ao conjunto do presente artigo. A palavra crença origina-se do grego Pistis ( credere, ambas significando o ato de entender algo como verdade, ou de buscar a verdade de algo. Para Abbbagnano, trata-se da atitude de quem reconhece como verdadeira uma posição ou sua validade. ${ }^{31}$

O ato de crer não implica em uma validade objetiva ou apenas de alcance religioso como é o caso do conceito de verdade (Emunah) que significa a esperança que algo se realize, crença em algo revelado, fé, mas ao contrário, crer expressa aceitar algo como verdade diante dos fatos daquele determinado momento.

\footnotetext{
LUHMANN, 1997.

MATHIS, 2004, p. 8.

9 WITTGENSTEIN, Ludwig. Tractatus Logico-Philosophicus. São Paulo: Cia. Editora Nacional/ EDUSP, 1968.

30 KUNZLER, C. M. Teoria dos sistemas de Niklas Luhmann. Estudos de Sociologia, Araraquara, n. 16, p. 123136, 2004. p. 126.

31 ABBAGNANO, 2000.
} 
Podem ser chamadas de crenças as conviç̧ões científicas tanto quanto as confissões religiosas, o reconhecimento de um princípio evidente ou de uma demonstração, bem como a aceitação de um preconceito ou de uma superstição. Mas não pode se chamar de crença a dúvida, que suspende a adesão à validade de uma noção, nem a opinião, no caso de excluir as condições necessárias para uma adesão desse gênero. ${ }^{32}$

Nesse sentido, ao longo de toda a história da filosofia, tal conceito se confunde corriqueiramente com o conceito de fé e coloca em xeque certos elementos e fatos tidos como verdade. Platão chamou de crença o tipo de conhecimento que tem por função as coisas sensíveis, por conterem uma adesão à realidade dessas coisas. Desse modo, a crença seria uma condição epistêmica. Já Agostinho considera a crença, algo que tem relação com as emoções.

Aristóteles considera que a crença não exclui a opinião e que não se deve crer como verdadeiros os pensamentos nos quais nos dispomos a crer. Já em Tomás de Aquino, crença e fé estão equiparadas e em concomitância à fé. Para Santo Tomás, "contém afirme adesão a um dos lados e nisso é semelhante ao ato de quem conhece e entende; todavia, o conhecimento de quem crê não é perfeito pela sua evidência, e nisso a crença está próxima da dúvida e da opinião". 33

Por sua vez, Champlin situa que a crença é momentânea por se tratar de um estágio na busca pelo conhecimento, caso não estejam disponíveis evidências mais conclusivas. ${ }^{34}$ Tal pensamento tem base em Locke, para quem, a limitação crítica do ato de conhecer, situado entre o certo (verdadeiro) e o provável (opinião), sendo que, o provável teria vários graus de adesão.

Em Descartes, a crença se mostra como um Gênio ruim, um pensamento que destrói inclusive as certezas mais profundas, de modo que ele constrói a ideia de crença como inerente à dúvida. O filósofo francês entende que o caminho para o conhecimento passa necessária e primeiramente pela crença, pela certeza passageira, mesmo que esta dure para sempre.

David Hume, escocês, a crença é um estado passível que ocorre ou deve ocorrer frente a alguma proposição. $O$ fato da mente inquerir a realidade e atribuir-lhe sentido e significado, mostra com a crença se apresenta como uma verdade de mesmo porte e força das demais verdades, pois é determinante em nossa maneira de ver os outros, de ver o mundo, de ver as coisas.

A crença em Hume, consiste em reconhecer a realidade de um objeto. Trata-se de uma concepção mais vívida e eficaz, firme e sólida, uma certeza daquilo que a imaginação por si só não fora capaz de construir. “O ato da mente que nos torna a realidade, ou o que

32 ABBAGNANO, 2000, p. 218.

33 ABBAGNANO, 2000, p. 218.

34 CHAMPLIN, 2005, p. 952. 
é tomado por realidade, mas presente do que as ficções, fazendo-a pesar mais sobre as emoções e a imaginação" ${ }^{35}$

Bebendo em Agostinho, Hume considera a crença algo inexplicável, entendendo-a simplesmente como a experiência ou sentimento natural e irredutível. Trata-se de uma experiência do espírito que distingue ideias do juízo de ficções da imaginação.

Como de praxe, Immanuel Kant endossa o pensamento de Hume a esse respeito, relacionando crença a opinião, a ciência e a fé. Nesse contexto, a crença seria tanto uma doxa, uma opinião, uma imagem, uma ideia sobre algo que se afirma como se fosse uma verdade; mas ela também é uma ciência, pois por mais que se saiba de algo, há sempre algo a se conhecer. Parafraseando Fernando Pessoa, “a verdade, se ela existe, ver-se-á que só consiste, na procura da verdade". Depois a crença é um fruto da fé, uma esperança, uma certeza, sem se ter certeza, "porque a vida, é só metade". Para Kant, a opinião seria uma espécie de crença, reconhecendo que carece de caráter de adesão, de modo que só a fé pode sofrer influência por demanda de adesão. ${ }^{36}$

É necessário fazer a distinção entre simples sugestão ao espírito de certa ordem entre as sensações ou ideias e a indicação de que essa ordem é um fato real que está acontecendo, que aconteceu uma ou mais vezes ou que acontece sempre em certas circunstâncias: que são as coisas indicadas como verdadeiras por uma predicação afirmativa ou como falsas pela negativa [...] juízo difere de representação, assim como as faculdades psíquicas, de modo que o juízo é marcado pela adesão da crença. ${ }^{37}$

Apesar de aparecer na teologia como correlata à fé, há que se fazer a ressalva de que se a fé é uma certeza cega, ou daquilo que não se vê, que não tem comprovação científica, a crença é ao contrário a certeza de que podemos conhecer aquilo que vemos, tocamos, sentimos, experimentamos. Aqui a crença tende a se parecer com a dúvida metódica proposta por Descartes.

Charles Peirce faz três distinções do conceito de crença enquanto compromisso com a ação: a crença é algo de que tomamos consciência; a crença aquieta a irritação da dúvida; a crença implica estabelecimento de uma regra da ação, como proporá Hume, um hábito. "Para desenvolver o significado de uma coisa, não devemos fazer mais do que determinar os hábitos que ela produz, pois aquilo que uma coisa significa é simplesmente o hábito que ela implica". ${ }^{38}$ Ainda segundo Charles Peirce, a identidade de um hábito depende de como ele nos levará a agir em todas as circunstâncias.

\footnotetext{
ABBAGNANO, 2000, p. 218.

ABBAGNANO, 2000, p. 219.

ABBAGNANO, 2000, p. 219.

ABBAGNANO, 2000, p. 219.
} 
Abbagnano traz o pensamento do autor Santayana, que dá uma conotação mística ao conceito de crença:

A conexão da crença está na parte ativa e prática do homem, ou seja, com a fome, o amor, a luta ou, de modo geral, a espera do futuro. Aquilo que se crê não é essência pura (que como tal é só objeto de intuição, mas uma coisa existente, e as coisas existentes se dão se dão somente na 'experiência animal', isto é, na relação de ação e reação do organismo com o mundo. [...] a crença na existência é uma 'fé animal'. ${ }^{39}$

Abbagnano ainda esclarece que a vida pode adquirir sentido e valor para quem acredita que ela os tem, mas que fora dessa esfera que ele chama de metafísica ao citar James, o fenômeno da crença é uma realidade hoje amplamente estudada, pois tudo o que se construiu como ciência não passa de crenças humanas, sendo crença tanto por nossa limitação natural, quanto pelo fato de que se convencionou que ciência é verdade e ponto final.

Para Lídia Prado, a cultura ocidental funda-se na crença, dado que explica o homem a partir de símbolos, signos e metáforas, ou seja, não o explica pelo que ele é e sim pelo que se acredita que ele é. ${ }^{40}$ Nesse sentido, vale ressaltar que mesmo a ciência, por mais racional que seja, baseia-se igualmente em crenças e evidência. Por certo, muito do que se afirmava há 10 anos não tem a mesma validade científica para os cientistas de hoje. Muitos erros foram cometidos, muitas falhas que custaram vidas, sobretudo no campo da saúde e da indústria alimentícia por exemplo.

Ainda para Lídia Prado, as crenças são uma espécie de modalidade existencial, ou seja, modelos de inserção no mundo real. ${ }^{41}$ Mesmo que o indivíduo não seja totalmente aceito, constrói a crença baseada em poucas evidências de que sou aceito nos meios que frequento e as pessoas gosto desse indivíduo.

Faz-se, portanto, necessário questionar se as crenças seriam ou não verdade? Para Lídia Prado, crenças são aproximações da realidade, desejo de conhecimento, forma de compreensão e inserção individual no mundo, sistema autoprotetivo. ${ }^{42}$

Para Henriques:

As motivações que conduzem à ação não podem ser hierarquizadas em relação ao seu conteúdo racional, dado que sua racionalidade ultrapassa a referência estrita às avaliações das consequências. Na medida em que não podemos ordenar completamente todos os resultados possíveis das

\footnotetext{
39 ABBAGNANO, 2000, p. 219.

40 PRADO, Lídia Reis de Almeida. Direito, Mitologia e Poesia: a Justiça como instrumento de vingança dos deuses. Revista Brasileira de Filosofia, n. 60, v. 237, p. 103-124, 2011.

41 PRADO, 2011.

42 PRADO, 2011.
} 
alternativas de que dispomos, essas alternativas não são comparáveis a partir de uma escala de graus de racionalidade. ${ }^{43}$

Desse modo, a realidade ou totalidade do mundo externo ao indivíduo é algo maior do que o próprio indivíduo; o todo é maior que a soma das partes. Assim, a compreensão desse indivíduo sobre a realidade será, claro, limitada, pois ele não possui três atributos básicos que são onipotência, onipresença e onisciência, dado que é humano, limitado, indivíduo situado em um único espaço-tempo.

Pode-se parafrasear Fernando Pessoa, no sentido de se afirmar que a crença é o nada que é o tudo. O homem num dado momento histórico se vê como homem, e não mais como animal sem consciência, e começa a se questionar quem ele é e onde ele está, em seguida, indaga sobre quem o colocou aqui, fenômenos estes que não acorrem a nenhum outro animal. À medida que busca explicação para o que em tese não tem explicação (o nada), constrói uma série de crenças (o tudo) que deixam esta nova forma de compreensão da realidade mais segura e confortável.

Não são poucas as vezes em que ao pensar estar investigando a realidade, o homem se põe a investigar o fruto de sua criação, ou seja, as suas crenças. Novamente ao encontrar respostas, ele por vezes e por um dado tempo, se dá por satisfeito.

Para Lídia Prado:

Estamos impregnados de carga simbólica, sendo, por isso [as crenças], molas propulsoras de uma sociedade. Por essa razão, acionam o desenvolvimento de uma nação segundo certos modelos por [elas] transmitidos, que são padrões de agir, pensar, sentir.44

Como foi colocado, a crença dá sentido ao mundo, ao homem e a seu próprio pensamento. Afinal, o que seria dos seres pensantes se não crescem em seu próprio cógito? Dessa maneira, passa-se a considerar o que seja o sistema de crenças em sua totalidade.

\section{O sistema de crenças}

Esse terceiro tópico discute o conceito de Sistema de Crenças a partir da ideia de religião enquanto estrutura autopoiética. Para tanto, inicialmente considera-se importante lançar mão de um juízo sobre o referido sistema. Se a crença pode ser definida como “[...] um 'condicionamento psicocognitivo' de acesso inteligível e explicativo da vida, do mundo e das coisas existentes. Ela pode ser definida também como 'fundamento

43 HENRIQUES, Ricardo. Comportamento racional e formação de crenças em Keynes. Rev. Bras. Econ., Rio de Janeiro, v. 54, n. 3, p. 359-379, set. 2000. Disponível em: <http://www.scielo.br/pdf/rbe/v54n3/a05v54n3.pdf>. Acesso em: 20 jun. 2017. p. 362.

44 PRADO, 2011, p. 108. 
intencional do agir'",45 um sistema seria um conjunto de indivíduos que atuam socialmente munidos de tais percepções intencionais sobre a realidade em que estão e constroem diariamente.

Nesse sentido, pode-se pensar que a religião faz parte de toda e qualquer sociedade de que se tem notícia, mesmo em épocas mais arcaicas, dado que onde está o indivíduo, está sua crença e a partir dela, a constituição das estruturas sociais; no entanto, tal afirmativa seria enfraquecida a partir do momento em que se pensasse a religião como centro do sistema social, dado que em cada sociedade ela se encontra dentro de especificidades locais. Para Bachur, "a religião não deve ser considerada um sistema social autopoiético tal como os demais". ${ }^{46}$ Tal fato se dá porque a religião é precedida em sua criação por um sistema de crenças que a cria e cria todas as demais estruturas.

A esse respeito, Luhmann entende que toda operação genuinamente social conduzida não pela consciência depurada da moldura comunicativa provida por sistemas funcionais, sofre uma interpenetração entre a produção de sentido nos sistemas sociais e a produção de sentido pelas consciências empíricas - e deve ser entendida como comunicação. ${ }^{47}$

Nesse contexto, a crença enquanto estrutura sistêmica, assim como a comunicação e a consciência, assumem um caráter simbólico autônomo com lógica peculiar a cada um. No entanto, mesmo assumindo um caráter simbólico, isso não garante que a crença tenha essencialmente um caráter de autopoiésis como a política, a economia, o direito e a ciência. Mas, segundo Barchur, Luhmann afirma em diversos momentos que a crença deve ser considerada um sistema autopoiético como os demais, dado que o sistema de crenças humanas que gera tais sistemas é em si uma autopoieses. Citando a estrutura religião:

[...] a religião se encontra hoje em uma sociedade cujas estruturas foram substituídas pela diferenciação funcional. Daí não decorre problema algum no fato de que também a religião encontra seu lugar como um sistema funcional entre os outros [...] a diferenciação funcional [Ausdifferenzierung] do sistema religioso conduz ao fechamento operacional e à reprodução autopoiética desse sistema [...]. Isso nos obriga a reconhecer que há, na moderna sociedade mundial, um sistema funcional para a religião que opera em bases mundiais e que se determina como religião, diferenciando-se dos demais sistemas funcionais. ${ }^{48}$

45 PIRES, Anderson Clayton. Sistema de estruturação de crenças sociointerativo: Estruturação de crenças, lógicas de interação e processos decontingenciamento. Psicólogo inFormação, ano 17, n, 17 jan./ dez. 2013. Disponível em: <http:/ / pesquisa.bvs.br/brasil/resource/pt/psi-67218>. Acesso em: 20 jun. 2017. p. 137.

46 BACHUR, João Paulo. A diferenciação funcional da religião na teoria social de Niklas Luhmann. Rev. bras. Ci. Soc., São Paulo, v. 26, n. 76, jun. 2011. Disponível em: <http://www.scielo.br/pdf/rbcsoc/v26n76/10.pdf>. Acesso em: 20 jun. 2017. p. 177.

47 LUHMANN apud BACHUR, 2011.

48 LUHMANN apud BACHUR, 2011, p. 178-179. 
Nesse sentido, a crença, assim como as demais estruturas, apenas assume o papel na construção ou estrutura social dentro de sua função utilitarista de estruturação autopoiética do indivíduo dentro do sistema social amplo; em outros termos

a especificidade da religião [crença] estaria no fato de que a participação na comunicação religiosa parece depender muito estreitamente do comprometimento e do engajamento efetivo da consciência [por sua vez sujeita à crença] - por intermédio da fé -, o que dificultaria a manutenção de sua fronteira sistema/ambiente. ${ }^{49}$

Somente pela diferenciação funcional é que o sistema religioso pode ter sentido autopoiético, o que dependerá também dentro do exposto inicialmente nesse tópico, do enquadramento coletivo da religião.

Todavia, se, no entanto, Luhmann reivindica para sua teoria da comunicação está no fato de conceber a religião como operação prática, de outro modo "trata-se de conceber a comunicação não como a transferência [Übertragung] de uma mensagem, como se fosse uma coisa, de uma consciência a outra". ${ }^{50}$

Dentro da visão do próprio Luhmann:

Pode-se atribuir à economia, à política, à ciência e, desde o século XVIII, também à educação o papel de âmbitos funcionais impulsionadores [da diferenciação funcional da sociedade]; à família e à religião ao contrário o papel de possibilitadores. [...] A passagem a uma sociedade funcionalmente diferenciada é impulsionada então por outros âmbitos funcionais. Por isso, a crescente diferenciação também do sistema da religião redunda como efeito colateral [Nebeneffekt]. As consequências atingem o sistema religioso de maneira negativa, e isso desde meados do século XVI, ou seja, antes que o sistema religioso precise reagir à secularização. [...] Reagir simultaneamente: (i) à não-identidade, crescentemente identificável, entre o sistema da sociedade e o sistema religioso; (ii) à diferenciação funcional da política, da ciência e da economia internamente à sociedade; (iii) à segmentação interna do sistema religioso; e, por fim, de maneira correlata a tudo isso, (iv) à crescente diferenciação entre o sistema da sociedade em face das pessoas individuais. ${ }^{51}$

A diferenciação funcional da religião e da sociedade se dá historicamente e de forma quase inevitável, tendo em vista que o sistema político e, portanto, secular, passa a incorporar a vida pública e citadina.

Para Brandão, "não é nada difícil observar o quanto à medida que se seculariza a sociedade brasileira - isto é, transfere valores, símbolos e poderes de uma esfera

49 BACHUR, 2011, p. 179.

50 BACHUR, 2011, p. 179.

51 LUHMANN apud BACHUR, 2011, p. 179-180. 
propriamente religiosa para outras esferas de códigos e linguagens de modo a construir conceitos que se tornam nomos". ${ }^{2}$

Nesse sentido, para Berger, a ideia de secularização tem origem na história das guerras religiosas em relação à tomada de terras. ${ }^{53}$ Mas atualmente é um conceito carregado de significados ideológicos e valorativos. A palavra se conecta diretamente à separação de Igreja e Estado, bem como à parte do clero da Igreja Católica que desempenha atividades voltadas ao público. Tem o mesmo sentido de Laicismo ou o governo é separado da religião.

Dentro do exposto, pode-se pensar que a secularização seria um fenômeno de cunho social que tem início com o processo de crescimento do poder e da autoridade da Igreja Católica do século VI até o século XII, podendo ter recebido esse nome em decorrência da virada de século no ano mil, tendo raízes também na ideia de que ao conseguir dominar o "mundo" como se entendia, estaria sendo preparada a vinda do Messias.

As sociedades ocidentais contemporâneas mudaram substantivamente sua relação com as religiões. Não mais questão de herança, mas opção pessoal, a escolha religiosa é condicionada e motivada por inúmeros fatores - de busca de respostas existenciais a soluções para necessidades mais urgentes da vida cotidiana. Abre-se então, um espaço para uma avaliação pessoal da religião e de seus agentes, desmistificando-os, em parte.

Talvez pelo exposto é que religião e sociedade passaram tantos séculos atreladas, dado que após a sua disjunção entre elas, tem-se uma via para a crescente fragmentação da ordem moral-cosmológica feudal. ${ }^{54}$

Weber talvez concorde com isso ao considerar que dentre as necessidades humanas está a de salvação cultivada dentro da religiosidade reivindicada como interesse direto daquela aparecendo de maneira natural como postulado de uma compensação individual. ${ }^{55}$ De mesmo modo, a religião cumpre um papel análogo ao da sociedade ao ter que transformar o indeterminável em determinado; trata-se, portanto, de um processo histórico de substituição de crenças.

Segundo Bachur:

As tensões identificáveis entre diferentes esferas de valor que possuem legalidades próprias [Eigengesetzlichkeiten] haviam permanecido latentes em função de uma integração moral, cosmológica e religiosa da ordem social, assegurada pelo menos até o Renascimento. O desencantamento do

52 BRANDÃO, Carlos Rodrigues. A cultura na rua. Campinas: Papirus, 1989. p. 15.

53 BERGER, Peter. O dossel sagrado: elementos para uma teoria sociológica da religião. São Paulo: Paulinas, 1985.

54 BARCUR, 2011, p. 180.

55 WEBER apud BARCUR, 2011, p. 180. 
mundo liberou legalidades próprias que muitas vezes estabelecem relações de tensionamento mútuo e que, por sua vez, não se permitem reconduzir a um processo monolítico de racionalização. ${ }^{56}$

Ainda para Bachur, a diferenciação funcional da religião está justamente no que Luhmann compreende por privatização da experiência religiosa. Para esse autor: "Podemos definir secularização como a relevância socioestrutural da privatização da decisão religiosa. Com isso, não se postula em última instância a perda de função ou de significado da religião, teórica ou conceitualmente". 57

Uma das explicações plausíveis dessa diferenciação funcional situa-se na multiplicidade interpretativa das imposições da crença. À medida que a experiência religiosa se torna individual, esta, também, foge ao controle de totalidade.

A Reforma Protestante aprofunda esta privatização particularizando um todo sacramental católico. Ainda para Luhmann:

A Privatização significa, para o âmbito religioso, que a participação na comunicação espiritual (igreja), assim como a crença na fé, tornou-se matéria de decisão individual; que somente pode-se esperar religiosidade sobre o fundamento de uma decisão individual e que esse fenômeno se tornou consciente. Enquanto o não acreditar era, antes disso, matéria privada, agora a crença torna-se matéria privada. ${ }^{58}$

Em todo o exposto, nota-se que a função clássica que a crença desempenha para a sociedade, à medida que o seu código simbólico permite compensar a exclusão sofrida pelo indivíduo nos demais sistemas. Assim, dispõe-se ao indivíduo o poder de tomar decisões de sua alcunha, incluindo-se nessa construção simbólica de sua sociedade.

Dentro da compreensão ou classificação social proposta por Niklas Luhmann, caso se queira pensar o mundo enquanto sistema, isso só poderia ser pensado inicialmente a partir de uma inteligência, seja cósmica, seja humana para se conceber, propor, construir e vivenciar esse ordenamento. Depois, deveria pensar-se um meio ambiente do mundo, e nesse, o conceito de mundo orientando o pensar, o deslocar-se ao meio ambiente, reconfigurando ainda que somente em conceito e consciência.

Depois da leitura crítico-interpretativa e descritiva de Niklas Lumann, é quase inevitável se pensar o homem dentro de duas dimensões concomitantes, que são o mundo e o sistema de mundo, no qual ou nos quais o ser está completamente imerso. A consciência (crença no conhecimento do todo) do mundo é de certo modo a existência do mundo. "Na medida em que algo existe, também o mundo existe. Todo o perigo da

\footnotetext{
56 BARCUR, 2011, p. 182.

57 LUHMANN apud BARCUR, 2011, p. 182.

58 LUHMANN apud BARCUR, 2011, p. 182-185.
} 
existência se deve pensar, pois, como possibilidade no mundo, toda a aniquilação da existência ocorre no mundo". 59

Por fim, o mundo em Luhmann pode ser dito como possibilidade e complexidade, estas, portanto independem do ser ou do homem. "Neste sentido, também a gnoseologia pressupõe a estrutura de um sistema cognitivo, em que radicam as condições de possibilidade do conhecimento". 60 Desse modo, entende-se que a complexidade do mundo depende dos sistemas e estruturas estabelecidas, de modo que, uma existência pode tornar-se uma ameaça à outra. A crença nesse contexto é apenas um dos elementos desse sistema em que pode promover a redução desse todo complexo. "O mundo não pode apreender-se como sistema, porque não tem nenhum "fora", frente ao qual ele se delimite. 61

\section{Conclusão}

O presente artigo procurou tratar sobre o sistema de crenças a partir dos conceitos de sistema, de crença e depois de sistema de crenças. Seu formato didático permite um primeiro olhar e ensaio sobre o tema que pretendemos desenvolver em nossas pesquisas daqui por diante. Acreditamos que o leitor pode perceber que tudo é uma questão não mais de como vemos, e sim de como cremos.

Espera-se que o leitor tenha ficado instigado a conhecer mais sobre esse universo vasto que são as crenças e que governam nossa vida no mundo.

Por fim, recomenda-se que outras investigações surjam a partir do presente texto, dado se crê, tratar-se de um campo novo que permeia as muitas áreas das Ciências da Religião e que assim tem muito a oferecer à compreensão que se tem do mundo, da sociedade e dos conceitos de realidade e totalidade, os quais iniciou-se uma discussão aqui.

\section{Referências}

ABBAGNANO, Nicola. Dicionário de filosofia. São Paulo: Martins Fontes, 2000.

BACHUR, João Paulo. A diferenciação funcional da religião na teoria social de Niklas Luhmann. Rev. bras. Ci. Soc., São Paulo, v. 26, n. 76, jun. 2011. Disponível em: <http://www.scielo.br/pdf/rbcsoc/v26n76/10.pdf>. Acesso em: 20 jun. 2017.

BELL, V.; HALLIGAN, P. W.; ELLIS, H. D. A Cognitive Neuroscience of Belief. In: HALLIGAN, Peter W.; AYLWARD, Mansel. The Power of Belief: Psychological Influence on Illness, Disability, and Medicine. Oxford: Oxford University Press, 2006.

\footnotetext{
59 SANTOS, José Manuel (Org.). O pensamento de Niklas Luhmann. Beira Interior: Universidade da Beira Interior, 2005. p. 71.

60 SANTOS, 2005, p. 73.

61 SANTOS, 2005, p. 75.
} 
BERGER, Peter. O dossel sagrado: elementos para uma teoria sociológica da religião. São Paulo: Paulinas, 1985.

BRANDÃO, Carlos Rodrigues. A cultura na rua. Campinas: Papirus, 1989.

CHAMPLIN, R. Enciclopédia de Bíblia, teologia e filosofia. São Paulo: Candeia, 2005.

HENRIQUES, Ricardo. Comportamento racional e formação de crenças em Keynes. Rev. Bras. Econ., Rio de Janeiro, v. 54, n. 3, p. 359-379, set. 2000. Disponível em: <http://www.scielo.br/pdf/rbe/v54n3/a05v54n3.pdf>. Acesso em: 20 jun. 2017.

KUNZLER, C. M. Teoria dos sistemas de Niklas Luhmann. Estudos de Sociologia, Araraquara, n. 16, p. 123-136, 2004.

LUHMANN, Niklas. Die Gesellschaft der Gesellschaft. Frankfurt am Main: Suhrkamp, 1997. . Funktion der Religion. Frankfurt am Main: Suhrkamp, 1977.

MATHIS, Armin. A sociedade na teoria dos sistemas de Niklas Luhmann. Presença, v. VIII, n. 28, maio 2004. Disponível em: <http://www.revistapresenca.unir.br/artigos_presenca/28arminmathias_asociedadenate oriadossistemas.pdf>. Acesso em: 17 jun. 2012.

PIRES, Anderson Clayton. Sistema de estruturação de crenças sociointerativo: Estruturação de crenças, lógicas de interação e processos decontingenciamento. Psicólogo inFormação, ano 17, n, 17 jan./dez. 2013. Disponível em: <http://pesquisa.bvs.br/brasil/resource/pt/psi-67218>. Acesso em: 20 jun. 2017.

PRADO, Lídia Reis de Almeida. Direito, Mitologia e Poesia: a Justiça como instrumento de vingança dos deuses. Revista Brasileira de Filosofia, n. 60, v. 237, p. 103-124, 2011.

ROMBACH, Heinrich. Leben des Geistes: Ein Buch der Bilder zur Fundamentalgeschichte der Menschheit. Freiburg/Basel/Wien: Herder, 1977.

SANTOS, José Manuel (Org.). O pensamento de Niklas Luhmann. Beira Interior: Universidade da Beira Interior, 2005.

WITTGENSTEIN, Ludwig. Tractatus Logico-Philosophicus. São Paulo: Cia. Editora Nacional/ EDUSP, 1968. 